\title{
Conversão de registros de representação semiótica: análise guiada pela teoria da relevância ${ }^{1}$
}

\section{Conversion of registers of semiotic representation: relevance-theoretic analysis}

\author{
Bazilicio Manoel de Andrade Filho ${ }^{2}$ \\ Fábio José Rauen ${ }^{3}$
}

\begin{abstract}
Resumo
Analisamos neste estudo como relações de relevância (Sperber \& Wilson, 1986, 1995) superordenam as atividades cognitivas de identificação de unidades significativas, de conversão e de tratamento em Matemática (Duval, 2008, 2009). Para tanto, aplicamos o mecanismo de interpretação guiado pela noção teórica de relevância à resolução equivocada de um problema de cálculo de volume de um prisma representando uma barra de ouro (Dante, 2005) por estudantes do terceiro ano do ensino médio. Os resultados demonstram que a proposição do problema em língua natural e a representação deitada da barra levaram os estudantes a mapear a sequência lexical 'altura da barra' corretamente como ALTURA DO TRAPÉZIO e incorretamente como ALTURA DO PRISMA. Isso sugere que os estudantes estão mobilizando o conceito ALTURA antes como aquilo que é vertical do que como um segmento de reta perpendicular às bases e compreendido entre elas.
\end{abstract}

Palavras-chave: teoria de registros de representação semiótica; pragmática cognitiva; teoria da relevância.

\begin{abstract}
We analyze in this study how relevance relations (Sperber \& Wilson, 1986, 1995) organize cognitive activities of identification of significant units, conversion and treatment in Mathematics (Duval, 2008, 2009). Therefore, we apply the relevance-theoretic interpretation mechanism in a wrong resolution of a calculus of the volume of a prism represented by a gold bar (Dante, 2005) by third year high school students. The results demonstrate that the proposition of the problem in natural language and the lying bar representation led students to map the lexical sequence 'altura da barra' (height of the bar) correctly as TRAPEZE HEIGHT and incorrectly as PRISM HEIGHT. This suggests that students are mobilizing HEIGHT as something that is vertical rather than the shortest line segment between the possibly extended bases.
\end{abstract}

Keywords: theory of registers of semiotic representation; cognitive-pragmatics; relevance theory.

\footnotetext{
${ }^{1}$ Os autores agradecem as pertinentes contribuições dos avaliadores de Zetetiké e de Marleide Coan Cardoso para a versão definitiva deste texto. Equívocos remanescentes são de nossa integral responsabilidade.

${ }^{2}$ Mestre e doutorando em Ciências da Linguagem pela Universidade do Sul de Santa Catarina. Professor do Instituto Federal de Santa Catarina, Campus de Criciúma, Brasil. Email: bazilicio.andrade@ifsc.edu.br.

${ }^{3}$ Doutor em Letras/Linguística pela Universidade Federal de Santa Catarina. Professor do Programa de Pósgraduação em Ciências da Linguagem da Universidade do Sul de Santa Catarina, Brasil. Email: fabio.rauen@unisul.br.
} 


\section{Considerações Iniciais ${ }^{4}$}

DOI: http://dx.doi.org/10.20396/zet.v25i2.8647171

Objetos matemáticos somente são acessíveis e perceptíveis por meio de registros de representação semiótica, cada qual dando conta de parte de suas propriedades conceptuais. Isso implica dizer que esses objetos formais nunca são apreendidos em sua totalidade, mas somente no domínio de potencialidades semióticas desses diferentes registros. Assim, a habilidade de transitar por diferentes formas de representação é, por hipótese, condição essencial para uma apreensão mais significativa dos objetos matemáticos e, como argumenta Duval (2008, 2009), primordial para ensinar e aprender Matemática.

Dominar diferentes registros de representação implica dominar as atividades cognitivas de identificar unidades significativas de cada registro, desenvolver tratamentos no domínio de cada um dos registros e converter unidades significativas de um registro de partida para um registro de chegada (Duval, 2008, 2009) ${ }^{5}$.

A mobilização dessas atividades cognitivas é fundamental na resolução ou na modelação de problemas. Por exemplo, resolver um problema de cálculo apresentado em língua natural implica identificar as unidades significativas desse registro, converter as proposições desse registro em uma representação matemática pertinente e, no domínio dessa representação pertinente, proceder aos tratamentos adequados. Esses processos demandam conhecimentos sobre as propriedades sintáticas (ordenação), semânticas (significado) e pragmáticas (possibilidades de ambiguidade e polissemia) características do registro de partida, que são essenciais para a interpretação correta do problema; conhecimentos precisos de pareamento das unidades significativas dos registros de partida e de chegada, que são essenciais para viabilizar a resolução do problema; e, por fim, conhecimentos das potencialidades de tratamento das unidades significativas do registro de chegada, que são essenciais para a resolução correta do problema.

Nestes processos, assumimos que os indivíduos produzem um balanço ótimo de custos e benefícios cognitivos. Uma teoria pragmático-cognitiva do processamento de linguagem que lida justamente com essas variáveis é a teoria da relevância de Sperber e Wilson $(1986,1995)$. Pensada em sua origem para as línguas naturais, a teoria da relevância assevera que estímulos comunicacionais funcionam como peças ostensivas de evidência para processos inferenciais complexos por meio dos quais os indivíduos mapeiam intenções do comunicador, muitas das quais sequer codificadas.

Para descrever e explicar esses processos, Sperber e Wilson formulam o conceito teórico de relevância, enquanto uma inequação na qual benefícios cognitivos devem superar esforços cognitivos necessários para processá-lo. Seguem desse conceito dois princípios: o princípio cognitivo de que a mente humana tende a maximizar a relevância dos inputs que processa, e o princípio comunicativo de que enunciados geram expectativas precisas de

\footnotetext{
${ }^{4}$ Este artigo deriva da dissertação de mestrado defendida em 2013 no Programa de Pós-Graduação em Ciências da Linguagem da Universidade do Sul de Santa Catarina (Andrade Filho, 2013). A investigação integra a linha de pesquisa Pragmática Cognitiva e Ensino de Matemática do Grupo de Pesquisa em Pragmática Cognitiva da Universidade do Sul de Santa Catarina.

${ }^{5} \mathrm{O}$ tratamento é uma operação cognitiva que corresponde a uma transformação de representação interna a um registro de representação ou a um sistema. A conversão é uma operação cognitiva que corresponde à transformação da representação de um objeto dada num registro em uma representação desse mesmo objeto num outro registro (Duval, 2009, pp. 57-58).
} 
DOI: http://dx.doi.org/10.20396/zet.v25i2.8647171

relevância ótima. Um enunciado é considerado otimamente relevante quando é suficientemente relevante para valer a pena processá-lo e, ao mesmo tempo, é o estímulo mais relevante consideradas as preferências e as habilidades do comunicador.

Importante para os propósitos deste artigo é o fato de a presunção de relevância ótima viabilizar um mecanismo de interpretação guiado pela relevância. Conforme esse mecanismo, diante de um estímulo comunicacional ostensivo qualquer, os indivíduos seguem uma rota de esforço mínimo na computação dinâmica e on-line de efeitos cognitivos, considerando hipóteses interpretativas em ordem de acessibilidade e parando quando o nível esperado de relevância é alcançado. Isso implica dizer que, diante da proposição de um problema matemático em língua natural, por exemplo, o mecanismo predirá que os indivíduos enriquecerão esses estímulos até torná-los explícitos o suficiente para compreendê-los e, sempre que necessário, os indivíduos gerarão implicações contextuais cotejando a interpretação em curso desses enunciados com suposições armazenadas em suas memórias enciclopédicas (conhecimento de mundo) até que a interpretação do problema satisfaça suas expectativas de relevância ótima.

Neste estudo, portanto, assumiremos a hipótese de trabalho de que relações de relevância superordenam as atividades de identificação de unidades significativas, de conversão e de tratamento de um problema proposto em língua natural e ilustrado por uma representação geométrica; e a hipótese operacional de que o concurso do mecanismo de interpretação guiado pela teoria da relevância permitirá descrever e explicar como essas atividades foram mobilizadas na resolução desse problema. Para avaliar essas hipóteses, analisamos a resolução que estudantes do terceiro ano do ensino médio de uma escola pública elaboraram do seguinte exercício de cálculo do volume de um prisma extraído do livro Matemática - volume único, de Luiz Roberto Dante (2005, p. 372):

Uma barra de ouro é fundida na forma de um prisma cuja base é um trapézio (figura a seguir). As bases desse trapézio medem $8 \mathrm{~cm}$ e $12 \mathrm{~cm}$ e a altura da barra é $5 \mathrm{~cm}$. O comprimento da barra é $30 \mathrm{~cm}$. Qual é seu volume?

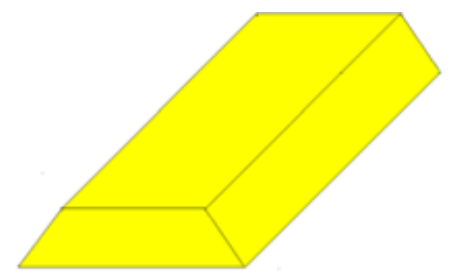

Durante a correção das atividades propostas no livro, verificamos que os estudantes não apresentaram dificuldades para determinar o volume de sólidos geométricos, com exceção do problema apresentado acima. $\mathrm{O}$ volume correto do prisma é de $1.500 \mathrm{~cm}^{3}$, mas a maioria dos estudantes apresentou $250 \mathrm{~cm}^{3}$ como resultado do cálculo. Diante dessa resposta, buscamos verificar qual foi a dificuldade que eles encontraram para obter a solução correta. A análise que segue é resultado desse processo.

\section{Processamento dos insumos linguísticos do problema ${ }^{6}$}

Para verificar como a arquitetura descritivo-explanatória da teoria da relevância pode ser aplicada à resolução de um problema matemático que demanda as três atividades

\footnotetext{
${ }^{6}$ Sobre a metodologia de análise, leia-se Rauen (2009).
} 
DOI: http://dx.doi.org/10.20396/zet.v25i2.8647171

cognitivas destacadas por Duval (2009), é preciso analisar como os enunciados linguísticos do problema são supostamente processados pelos estudantes. A teoria da relevância assume que enunciados linguísticos são encaixados em formas lógicas. Estas formas lógicas dispõem as entradas lógicas essenciais que são necessárias para a explicitação das informações expressas nas proposições que compõem o problema que, por sua vez, permitem estabelecer valor de verdade para essas proposições. Se o enunciado do problema é plenamente explícito, cada um desses elementos pareará entradas lexicais codificadas - as unidades significativas do registro em língua natural em nosso exemplo - com entradas enciclopédicas conceptuais os conceitos, de modo que todas as informações necessárias para atribuir valor de verdade para cada proposição do problema estão registradas na sentença. Todavia, enunciados linguísticos são, em geral, menos que plenamente explícitos, demandando do intérprete que ele infira entradas conceptuais adequadas de elementos parcialmente codificados e mesmo até de elementos não codificados. Esse processo inferencial de preenchimento de entradas lógicas gera a explicatura desses enunciados. Além disso, nem sempre as explicaturas dos enunciados expressam as intenções últimas do proponente do exercício. A rigor, a proposição de um problema em Matemática não requer que o estudante apenas interprete suas sentenças, mas o resolva. Isso demanda pelo menos os seguintes processos inferenciais:

a) Inferir pareamentos corretos entre as entradas fornecidas pelo registro de partida e as respectivas entradas do registro de chegada necessários para resolver o problema. No caso em pauta, pelo menos parear os insumos do problema em língua natural com respectivas unidades significativas do registro algébrico - o que corresponde à atividade de conversão entre pelo menos esses dois registros;

b) Obter a resposta do problema no domínio de possibilidades do registro algébrico, - o que corresponde à atividade de tratamento no interior do registro de chegada;

c) Parear a resposta obtida no escopo do registro algébrico com a respectiva unidade significativa do registro em língua natural - conversão necessária para responder o problema formulado em língua natural.

Esse complexo conjunto de inferências - denominadas de implicaturas em teoria da relevância - mobilizará cadeias expressivas de premissas e conclusões implicadas, e o objetivo da análise que segue é observar como o mecanismo de interpretação guiado pela noção teórica de relevância superordena esses processos.

Vejamos a interpretação da primeira sentença do problema:

(1) Uma barra de ouro é fundida na forma de um prisma cuja base é um trapézio (figura a seguir).

Em teoria da relevância, podemos descrever a elaboração de explicaturas de enunciados em sucessivas camadas de complexidade. Neste artigo, propomos quatro camadas de descrição. Na versão (1a), apresentamos a estrutura linguística da sentença; na versão (1b), descrevemos as entradas lógicas necessárias para interpretar a sentença; na versão (1c), apresentamos os preenchimentos das entradas lógicas, de modo a compor a explicatura; e, na versão (1d), encaixamos a explicatura numa descrição que engloba o ato proposicional 
DOI: http://dx.doi.org/10.20396/zet.v25i2.8647171

pertinente. Vejamos como a primeira sentença pode ser descrita nestes termos:

(1a) Uma barra de ouro é fundida na forma de um prisma cuja base é um trapézio (figura a seguir).

(1b) (ser fundida x, $\left.\alpha_{\text {modo }}(\operatorname{ser} \mathrm{x}, \mathrm{y})\right) \wedge(\text { representar } \mathrm{x}, \mathrm{y})^{7}$.

(1c) UMA BARRA DE OURO É FUNDIDA NA FORMA DE UM PRISMA CUJA BASE [DO PRISMA] É UM TRAPÉZIO $\varnothing$ [E] [A] FIGURA A SEGUIR $\varnothing$ [REPRESENTA] $\varnothing$ [UMA BARRA DE OURO FUNDIDA NA FORMA DE UM PRISMA CUJA BASE DO PRISMA É UM TRAPÉZIO] $]^{8}$.

(1d) O PROBLEMA AFIRMA QUE UMA BARRA DE OURO NA FORMA DE UM PRISMA CUJA BASE DO PRISMA É UM TRAPÉZIO E A FIGURA A SEGUIR REPRESENTA UMA BARRA DE OURO FUNDIDA NA FORMA DE UM PRISMA CUJA BASE DO PRISMA É UM TRAPÉZIO.

A descrição (1b) captura que a primeira sentença do problema apresenta, a rigor, três proposições. As duas primeiras proposições formam um conjunto conectado pelo pronome relativo 'cujo'. A primeira proposição é a de que "algo (UMA BARRA DE OURO $_{\mathrm{x}}$ ) é fundido numa forma ${ }_{\text {amodo }}$ (FORMA DE UM PRISMA amodo $_{\text {)". A segunda é a de que "a base desta forma }}$ (A BASE DO PRISMA $A_{x}$ ) é um trapézioy". A terceira proposição dá conta da informação entre parênteses de que "algo $\left(\mathrm{a}\right.$ figura a seguir $\mathrm{x}_{\mathrm{x}}$ ) representa $\operatorname{algo}_{\mathrm{y}}$ (uma barra de ouro fundida na forma de um prisma cuja base do prisma é um trapézio y)"

Por hipótese, esse enunciado mobiliza as suposições $\mathrm{S}_{1-3}$ como premissas implicadas ${ }^{10}$ :

$\mathrm{S}_{1}$ - Uma barra de ouro é fundida na forma de um prisma (premissa implicada do input linguístico);

$\mathrm{S}_{2}-\mathrm{A}$ base do prisma é um trapézio (premissa implicada do input linguístico);

$\mathrm{S}_{3}$ - A figura do problema representa uma barra de ouro fundida na forma de um prisma cuja base do prisma é um trapézio (premissa implicada do input linguístico).

\footnotetext{
${ }^{7}$ Nesta formulação, cada proposição lógica está representada entre parênteses; verbos ou locuções verbais ocupam a posição mais à esquerda da representação; os termos da proposição são sucessivamente representados pelas letras ' $x, y, z$ '; e as circunstâncias são representadas por letras gregas ' $\alpha, \beta$, $\gamma$, etc.'. Relações lógicas entre proposições são representadas pelos símbolos ‘ $\wedge(\mathrm{e}), \vee(\mathrm{ou}), \rightarrow$ (implicação), etc.', conforme o caso.

${ }^{8}$ As entradas enciclopédicas são representadas em versaletes minúsculos. Observe-se que não mais se tratam de entradas lexicais (unidades significativas nos termos de Duval (2009)), mas de entradas conceptuais. O símbolo ' $\varnothing$ ' representa que há uma elipse da entrada lexical pertinente na formulação linguística. As informações parcialmente codificadas que demandam por complementação inferencial são representadas entre colchetes.

${ }^{9}$ A rigor, essa informação demanda pela conversão de informações figurais, como se verá adiante.

${ }^{10}$ As suposições $S_{1-n}$ são peças de informação que alimentam processos inferenciais. Quando fundamentam inferências, elas são denominadas de premissas implicadas, quando são o resultado de inferências, elas são denominadas de conclusões implicadas. Embora sejam constituídas de entradas enciclopédicas ou conceptuais, elas não serão formuladas em versaletes minúsculos por razões estéticas.
} 
DOI: http://dx.doi.org/10.20396/zet.v25i2.8647171

Passemos para o segundo enunciado, referente às medidas do trapézio ${ }^{11}$ :

(2a) As bases desse trapézio medem $8 \mathrm{~cm}$ e $12 \mathrm{~cm}$ e a altura da barra é $5 \mathrm{~cm}$.

Por hipótese, esse enunciado mobiliza as premissas implicadas $\mathrm{S}_{4-5}$ :

$\mathrm{S}_{4}-$ As bases trapézio da barra de ouro medem $8 \mathrm{~cm}$ e $12 \mathrm{~cm}$ (premissa implicada do input linguístico);

$\mathrm{S}_{5}$ - A altura da barra de ouro cuja base é um trapézio é $5 \mathrm{~cm}$ (premissa implicada do input linguístico).

O terceiro enunciado refere-se ao comprimento da barra:

(3a) O comprimento da barra é $30 \mathrm{~cm}$.

Por hipótese, o terceiro enunciado acrescenta a premissa $\mathrm{S}_{6}$ :

$\mathrm{S}_{6}-\mathrm{O}$ comprimento da barra de ouro cuja base é um trapézio é $30 \mathrm{~cm}$ (premissa implicada do input linguístico).

O quarto enunciado contém o comando da questão na forma de uma pergunta de exame. Em perguntas de exame, o estudante precisa recuperar sua forma lógica e integrá-la numa descrição com a forma $O$ falantelescritor pergunta $Q U-P$, em que $Q U-P$ é uma pergunta indireta. Para Sperber e Wilson (2001, p. 371), numa pergunta de exame, "a sugestão é que a resposta será relevante para a pessoa falante, não tanto pelo seu conteúdo, como pela evidência indireta que fornece quanto ao domínio da matéria pelo candidato".

Em outras palavras, é desejável, do ponto de vista do proponente do exercício, que o estudante seja capaz de fornecer o valor correto do volume da barra de ouro. Ou mesmo, sabe-se que "algo $\mathrm{x}_{\mathrm{x}}(\mathrm{O}$ VALOR DO VOLUME DA BARRA DE OURO EM FORMATO DE UM PRISMA CUJA BASE É UM TRAPÉZIO ${ }_{x}$ ) possui um valor ${ }_{\mathrm{y}}$ ”. O pronome interrogativo 'qual' coloca-se justamente no lugar desse valor que ainda é incógnito para o estudante, embora não seja incógnito para o professor, e o estudante sabe que o professor sabe a resposta. A rigor, todo jogo comunicativo consiste em encontrar este valor.

Por hipótese, o quarto enunciado acrescenta a premissa $S_{7}$ :

$\mathrm{S}_{7}-\mathrm{O}$ proponente do problema pergunta qual é o valor do volume da barra de ouro em formato de um prisma cuja base é um trapézio (premissa implicada do input linguístico).

\section{Procedendo ao cálculo}

As suposições $\mathrm{S}_{1-7}$ supostamente formam o conjunto de insumos (inputs) necessários para calcular o volume da barra de ouro. Nesta seção, perseguiremos uma de muitas cadeias de inferências possíveis para resolver o problema em pauta, assumindo o risco de ela não ser necessariamente o único caminho seguido pelos estudantes.

Nesta simulação de cadeias de inferências, um conhecimento importante a ser

\footnotetext{
${ }^{11}$ Por constrições de espaço, assumimos que o leitor é capaz de inferir os passos descritivos de cada uma das sentenças subsequentes do exercício.
} 
DOI: http://dx.doi.org/10.20396/zet.v25i2.8647171

mobilizado é o da fórmula do cálculo de volume de prismas. Para mobilizá-lo, é preciso, converter proposições em língua natural em proposições em registro algébrico, embora reconheçamos que a conversão pode e, como veremos adiante, deve envolver uma combinação mais complexa incluindo conversões entre a língua natural e o registro geométrico, e entre os registros geométrico e algébrico. Arbitrariamente, proporemos a precedência da primeira conversão para efeitos descritivos.

A fórmula para o cálculo do volume é a que segue:

$$
V=A_{b} \cdot h
$$

Por hipótese, para mobilizar essa fórmula, o estudante deve ter memorizado a seguinte suposição (aqui representando uma versão mais recorrente de expressão entre os estudantes):

$\mathrm{S}_{8}-\mathrm{O}$ volume de um prisma é igual à área da base do prisma vezes a altura do prisma (premissa implicada da memória enciclopédica).

Com base nessa suposição, começa a cadeia de inferências necessária para a resolução do problema. Uma primeira é a de que, se o volume do prisma corresponde ao produto da área da base pela altura, então é preciso calcular a área da base primeiro.

$\mathrm{S}_{8}-\mathrm{O}$ volume de um prisma equivale à área da base do prisma vezes a altura do prisma (premissa implicada da memória enciclopédica);

$\mathrm{S}_{9}-\mathrm{S}_{8} \rightarrow \mathrm{S}_{10}$ (inferência por modus ponens) ${ }^{12}$;

$\mathrm{S}_{10}$-É preciso calcular primeiro a área da base do prisma (conclusão implicada).

$\mathrm{S}_{11}=\mathrm{S}_{2}-\mathrm{A}$ base do prisma é um trapézio (premissa implicada do input linguístico);

$\mathrm{S}_{12}-\mathrm{S}_{10} \wedge \mathrm{S}_{11} \rightarrow \mathrm{S}_{13}$ (inferência por modus ponens conjuntivo);

$\mathrm{S}_{13}$-É preciso calcular a área do trapézio (conclusão implicada).

Para determinar a área do trapézio, é preciso mobilizar a fórmula:

$$
A=\frac{(B+b) \cdot h}{2}
$$

Para mobilizar essa fórmula, o estudante deve ter memorizado a seguinte suposição:

$\mathrm{S}_{14}$ - A área do trapézio é igual à soma das bases do trapézio vezes a altura do trapézio dividido por 2 (premissa implicada da memória enciclopédica).

Com base na fórmula, o estudante volta ao enunciado do problema e mapeia as informações em ordem de acessibilidade (da esquerda para a direita) até encontrar os insumos

\footnotetext{
${ }^{12}$ A teoria da relevância concebe haver na cognição humana um módulo interpretativo de caráter dedutivo, operando prevalentemente por regras de eliminação, especialmente, eliminação-e e modus ponens. Numa regra de eliminação-e, sendo consideradas em conjunto verdadeiras duas suposições $P$ e $Q$, cada uma delas é verdadeira separadamente, $P$ ou $Q$. Formalmente: " $\mathrm{P} \wedge \mathrm{Q}, \mathrm{P}$ " ou " $\mathrm{P} \wedge \mathrm{Q}, \mathrm{Q}$ " (o símbolo ' $\wedge$ ' equivale à operação lógica de adição). Numa regra de modus ponens, se há uma relação de implicação entre duas suposições $P$ e $Q$, quando a primeira é afirmada $P$, segue-se necessariamente a segunda $Q$. Formalmente: " $\mathrm{P} \rightarrow \mathrm{Q}, \mathrm{P}, \mathrm{Q}$ " (o símbolo ' $\rightarrow$ ' equivale à operação lógica de implicação, se $\mathrm{P}$ então $\mathrm{Q}$ ). Por vezes, é possível combinar as duas regras como é o caso da regra de modus ponens conjuntivo: " $(\mathrm{P} \wedge \mathrm{Q}) \rightarrow \mathrm{R}, \mathrm{P} \rightarrow \mathrm{R}, \mathrm{R}$ ” ou então "( $\mathrm{P} \wedge \mathrm{Q}) \rightarrow \mathrm{R}, \mathrm{Q} \rightarrow \mathrm{R}, \mathrm{R}$ ".
} 
DOI: http://dx.doi.org/10.20396/zet.v25i2.8647171

da fórmula, a saber: as bases maior e menor e a altura. Os dados das bases do trapézio estão no segundo enunciado.

$\mathrm{S}_{15}=\mathrm{S}_{4}-$ As bases trapézio da barra de ouro medem $8 \mathrm{~cm}$ e $12 \mathrm{~cm}$ (premissa implicada do input linguístico);

A determinação da altura do trapézio depende de o estudante inferir que a expressão 'altura da barra' corresponde à altura do trapézio.

$\mathrm{S}_{16}=\mathrm{S}_{5}-\mathrm{A}$ altura da barra de ouro cuja base é um trapézio é $5 \mathrm{~cm}$ (premissa implicada do input linguístico);

$\mathrm{S}_{17}$ - A altura da barra corresponde à altura do trapézio (premissa implicada da memória enciclopédica);

$\mathrm{S}_{18}-\mathrm{S}_{16} \wedge \mathrm{S}_{17} \rightarrow \mathrm{S}_{19}$ (inferência por modus ponens conjuntivo);

$\mathrm{S}_{19}$ - A altura do trapézio é $5 \mathrm{~cm}$ (conclusão implicada).

Com essas suposições, é possível empreender o tratamento correto para calcular a área do trapézio, terceira atividade cognitiva nos termos de Duval $(2009)^{13}$ :

$$
A=\frac{(B+b) \cdot h}{2}=\frac{(12+8) \cdot 5}{2}=\frac{20 \cdot 5}{2}=50 \mathrm{~cm}^{2}
$$

Com esse tratamento, é possível chegar ao resultado:

$\mathrm{S}_{20}$ - A área do trapézio é $50 \mathrm{~cm}^{2}$ (conclusão implicada derivada do tratamento matemático).

Conhecida a área do trapézio, pode-se passar ao cálculo do volume do prisma. Para isso, é necessário recuperar a altura do prisma do enunciado do problema. Mais uma vez, entra em cena o mecanismo de compreensão guiado pela relevância. Para isso, o estudante deve considerar "hipóteses interpretativas (desambiguações, atribuições referenciais, suposições contextuais, implicaturas, etc.) seguindo a ordem de acessibilidade" e parar "quando é alcançado o nível esperado de relevância" (Sperber \& Wilson, 2001, p. 13). Ocorre que a palavra 'altura' aparece pela primeira e única vez na expressão 'altura da barra' na segunda proposição do segundo enunciado. Sendo esse o caso, é possível que o estudante mobilize as seguintes suposições:

$\mathrm{S}_{21}=\mathrm{S}_{1}$ - Uma barra de ouro é fundida na forma de um prisma (premissa implicada do input linguístico);

$\mathrm{S}_{22}=\mathrm{S}_{5}-\mathrm{A}$ altura da barra de ouro cuja base é um trapézio é $5 \mathrm{~cm}$ (premissa implicada do input linguístico);

$\mathrm{S}_{23}-\mathrm{S}_{21} \wedge \mathrm{S}_{22} \rightarrow \mathrm{S}_{24}$ (inferência por modus ponens conjuntivo);

$* \mathrm{~S}_{24}$ - A altura do prisma é $5 \mathrm{~cm}$ (conclusão implicada).

Conhecida a altura do prisma (sic), o estudante pode empreender o tratamento para calcular o volume do prisma:

\footnotetext{
${ }^{13}$ Por constrições de espaço, as suposições mobilizadas para o cálculo não serão descritas.
} 


$$
V=A_{b} \cdot h=50 \cdot 5=250 \mathrm{~cm}^{3}
$$

Com esse tratamento, é possível chegar a $250 \mathrm{~cm}^{3}$ como resultado:

$\mathrm{S}_{25}-\mathrm{O}$ volume do prisma é de $250 \mathrm{~cm}^{3}$ (conclusão implicada derivada do tratamento matemático).

\section{Discussão do resultado}

Segundo assevera o mecanismo de interpretação guiado pela relevância, a primeira interpretação consistente com a presunção de relevância ótima é a interpretação relevante. Isso explicaria por que o estudante, tendo obtido o volume do prisma, ignora as informações do terceiro enunciado. Desse modo, tendo obtido o volume de $250 \mathrm{~cm}^{3}$ como resposta, o estudante dá o problema como encerrado e passa para a próxima tarefa.

Seguindo o procedimento de compreensão guiado pela relevância, o estudante teria processado os enunciados linguísticos numa suposta cadeia de suposições $\left(S_{1}-S_{25}\right)$. Nessa cadeia, a suposição $S_{24}$ configura-se como uma conclusão implicada que decorre de duas premissas implicadas. A primeira $S_{21}$ produz a equivalência entre as sequências lexical 'barra de ouro' e 'forma de um prisma'. Em outras palavras, a barra de ouro é um prisma. No segundo enunciado, afirma-se que a altura da barra de ouro mede $5 \mathrm{~cm}$. Isso permite inferir que, sendo equivalentes os termos 'barra de ouro' e 'forma do prisma' e sendo $5 \mathrm{~cm}$ a altura da barra de ouro, então também será $5 \mathrm{~cm}$ a altura do prisma. Nada mais havendo a interpretar (ou seja, tendo sido encontrada a interpretação relevante), procede-se ao cálculo.

Vejamos:

$\mathrm{S}_{21}=\mathrm{S}_{1}-$ Uma barra de ouro é fundida na forma de um prisma (premissa implicada do input linguístico);

$\mathrm{S}_{22}=\mathrm{S}_{5}-\mathrm{A}$ altura da barra de ouro cuja base é um trapézio é $5 \mathrm{~cm}$ (premissa implicada do input linguístico);

$\mathrm{S}_{23}-\mathrm{S}_{21} \wedge \mathrm{S}_{22} \rightarrow \mathrm{S}_{24}$ (inferência por modus ponens conjuntivo);

$\mathrm{S}_{24}$ - A altura do prisma é $5 \mathrm{~cm}$ (conclusão implicada).

A origem do equívoco está na dupla atribuição de referência ao termo 'altura' nas duas fórmulas. Quando o estudante procede ao tratamento do cálculo da área do trapézio, o termo 'altura da barra' é corretamente mapeado como altura do trapézio, ou seja, ao segmento de reta que é perpendicular às bases e é compreendido entre elas. Reparemos que não há problema de conversão ou de tratamento, e o resultado obtido é o resultado esperado. Quando o estudante procede ao tratamento do cálculo do volume do prisma, a expressão 'altura da barra' não pode ser mapeada por altura do prisma, embora tivesse havido antes a equivalência entre barra e prisma no primeiro enunciado, como já argumentamos. Agora há um problema de conversão, embora não haja erro de tratamento, visto que o algoritmo do cálculo segue corretamente com premissas ou insumos incorretos.

Para que o estudante tenha condições de compreender o que ocorreu na questão, o docente precisa retomar o conceito de altura de um prisma. Altura de um prisma corresponde à distância perpendicular entre as duas bases, ou melhor, a distância que forma um ângulo de Zetetiké, Campinas, SP, v.25, n.2, maio./ago.2017, p.289-304.

ISSN 2176-1744 
DOI: http://dx.doi.org/10.20396/zet.v25i2.8647171

$90^{\circ}$ entre as duas bases. Sendo a barra de ouro fundida na forma de um prisma cuja base é um trapézio, a altura do prisma não pode ser encontrada no próprio trapézio, mas sim na aresta lateral da barra. É o terceiro enunciado que se refere à aresta lateral da barra com $30 \mathrm{~cm}$ de comprimento. Nesse caso, é necessário mostrar ao estudante que o prisma se encontra deitado, mobilizando o registro geométrico. Com base nessa mobilização, o estudante perceberia que a) as faces laterais (com a forma de um trapézio) coincidem com a base do prisma; b) a expressão 'altura da barra' deve corresponder ao conceito de altura do trapézio em vez de altura do prisma; e c), e a expressão 'comprimento da barra de ouro' deve corresponder ao conceito de altura do prisma.

Vejamos, a seguir, uma suposta cadeia de inferências necessária para resolver adequadamente a questão:

$\mathrm{S}_{21}$, $=\mathrm{S}_{1}$ - Uma barra de ouro é fundida na forma de um prisma (premissa implicada do input linguístico);

$\mathrm{S}_{22}$, $=\mathrm{S}_{6}-\mathrm{O}$ comprimento da barra de ouro cuja base é um trapézio é $30 \mathrm{~cm}$ (premissa implicada do input linguístico);

$\mathrm{S}_{23}$, - O prisma encontra-se deitado (premissa implicada do input visual);

$\mathrm{S}_{24},-\mathrm{S}_{22}, \wedge \mathrm{S}_{23}, \rightarrow \mathrm{S}_{25}$ ' (inferência por modus ponens conjuntivo);

$\mathrm{S}_{25}$, - $\mathrm{O}$ comprimento da barra de ouro equivale à altura do prisma (conclusão implicada);

$\mathrm{S}_{26},-\mathrm{S}_{22^{\prime}} \wedge \mathrm{S}_{25}, \rightarrow \mathrm{S}_{27}$ (inferência por modus ponens conjuntivo);

$\mathrm{S}_{27}$ - A altura do prisma é $30 \mathrm{~cm}$ (conclusão implicada).

Mapeada corretamente a altura do prisma, é possível realizar o cálculo correto do volume do prisma:

$$
V=A_{b} \cdot h=50 \cdot 30=1.500 \mathrm{~cm}^{3}
$$

Com esse tratamento, é possível chegar ao resultado esperado:

$\mathrm{S}_{28}$, $\mathrm{O}$ volume do prisma é $1.500 \mathrm{~m}^{3}$ (conclusão implicada derivada do tratamento matemático).

\section{Causas do equívoco}

Segundo assevera a presunção de relevância ótima, um enunciado presume-se otimamente relevante porque é o estímulo mais relevante que o falante/escritor foi capaz ou quis produzir. $\mathrm{Na}$ resolução do exercício em questão, mobilizam-se três registros de representação, cada um dos quais exercendo influências próprias no processamento do problema. Até o momento, chegamos à conclusão que o estudante teria mapeado incorretamente altura da barra por altura do prisma. A questão remanescente é por quê?

Uma hipótese é a de que um conceito mais fundamental para o termo 'altura' afetou tanto a proposição como a interpretação do exercício. Tomemos o conceito de altura do dicionário Michaelis online (2013). 
DOI: http://dx.doi.org/10.20396/zet.v25i2.8647171

sf (alto+ura2) 1 Distância perpendicular de baixo para cima; profundidade; espessura. 2 Distância entre o ponto mais baixo e o ponto mais alto de alguma coisa ereta: A altura de um prédio, de uma árvore. 3 Distância entre o ponto mais baixo e o mais alto de um corpo animal, especialmente do homem; tamanho, estatura. [...]. (negritos nossos acrescentados ao original).

Apesar de a primeira acepção do item lexical 'altura' remeter à "profundidade" e à "espessura", mais próximas da noção técnica do termo ligada ao conceito do que é perpendicular às bases, a maior parte das acepções do termo 'altura' remetem ao conceito do que é vertical, que são destacadas em negrito na citação. Termos como 'ponto mais baixo' e 'ponto mais alto', por exemplo, estão intrinsecamente relacionados com essa noção primeira e mais intuitiva de 'altura'.

Se isso estiver correto, o exercício está mobilizando pelo menos três conceitos de ALTURA, a saber: (1) ALTURA, como algo que se define antes por aquilo que é vertical e mobiliza conceitos como EM CIMA e EMBAIXO; (2) ALTURA*, um primeiro estreitamento técnico que se refere ao conceito de ALTURA DE UM TRAPÉZIO, ou seja, um segmento de reta que é perpendicular às bases e é compreendido entre elas; e (3) ALTURA**, um segundo estreitamento técnico que se refere ao conceito de ALTURA DE UM PRISMA, ou seja, uma distância que forma um ângulo de $90^{\circ}$ entre as duas bases de um prisma.

Além disso, o exercício está mobilizando simultaneamente três objetos, a saber: (4) barra de ouro, um objeto empírico que pode ser concebido com um prisma de vários formatos, incluindo aqueles cuja base é um trapézio; (5) trapézio, um objeto geométrico bidimensional cujo acesso só se pode dar por meio de suas representações e, no caso em questão, representando a base da barra de ouro; (6) prisma, um objeto geométrico tridimensional cujo acesso também só se pode dar por meio de suas representações e, no caso em questão, representando tridimensionalmente a barra de ouro.

Posto isso, podemos ter as seguintes combinações plausíveis:

a) ALTURA da barra de ouro;

b) ALTURA do trapézio;

c) ALTURA do prisma;

d) ALTURA* do trapézio;

e) ALTURA** do prisma.

Mais ainda, o exercício está mobilizando três registros que demandam conversões mútuas: (7) o registro em língua natural; (8) o registro geométrico; e (9) o registro algébrico, de modo que a proposição da tarefa se inicia pelo registro em língua natural, passa pelo registro geométrico e termina no registro algébrico.

O registro algébrico demanda apenas as combinações (d) e (e) para as fórmulas do cálculo da área do trapézio e do volume do prisma. Todavia, o exercício fornece explicitamente essas combinações? No registro em língua natural, o termo altura aparece apenas uma vez no segundo enunciado em 'altura da barra', e essa expressão é facilmente mapeada na figura da barra. Vejamos: 
DOI: http://dx.doi.org/10.20396/zet.v25i2.8647171

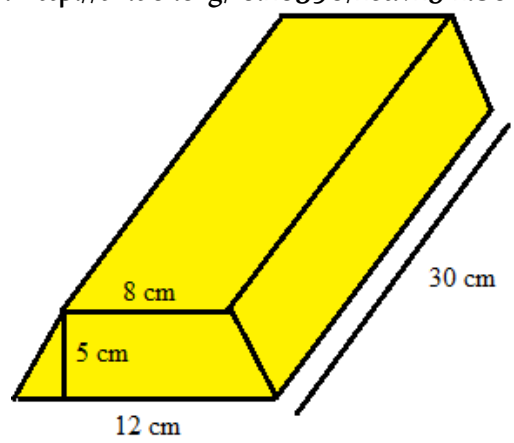

Figura 1 - Representação da barra de ouro

Fonte: Dante (2005, p. 372) com acréscimo de medidas

Um estudante, mesmo que ainda não tenha domínio do conceito técnico de ALTURA* (altura do trapézio), pode interpretar $5 \mathrm{~cm}$ como altura, uma vez que ela está representada verticalmente na figura e, de fato, representa corretamente a altura desses objetos empíricos quando estão deitados. Nada há de errado com a expressão 'altura da barra': ela representa a altura vertical das barras deitadas (combinação a) tanto quanto, no caso, o segmento de reta que é perpendicular às bases do trapézio e é compreendido entre elas (combinação b). Como não há problema de conversão entre língua natural e registro geométrico, não há erro de conversão no cálculo da área do trapézio.

Mas que dizer de altura do prisma. Primeiro, o termo não surge explicitamente no registro em língua natural: é preciso inferir o conceito ALTURA** do item lexical 'comprimento', e isso demanda conhecimento do conceito de altura como algo perpendicular às bases. Segundo, como a barra está deitada, a ALTURA** está representada no eixo z, que, obviamente, não está na vertical.

$\mathrm{Na}$ figura 2, ao girar a barra de ouro $^{14}$, pretendemos demonstrar como o conceito ALTURA** relaciona-se com a formação de um ângulo de $90^{\circ}$ em relação às suas bases e não com a noção de verticalidade (eixo y). Em outras palavras, quando o prisma está deitado, ou seja, representando suas bases verticalmente (eixos x e y), a altura do prisma será representada pela profundidade (eixo z). Quando o prisma está em pé, ou seja, as bases ficando embaixo e sobre as arestas laterais (eixos x e z) a altura do prisma será representada verticalidade (eixo y) ${ }^{15}$.

\footnotetext{
${ }^{14}$ Como se verá mais à frente, ao fazer esse giro, modifica-se intrinsecamente o problema.

15 A rigor, trata-se de um problema insolúvel. Ou a representação privilegia a altura do trapézio, apresentando a barra de ouro deitada, ou a representação privilegia a altura do prisma, apresentando a barra de ouro em pé.
} 
DOI: http://dx.doi.org/10.20396/zet.v25i2.8647171
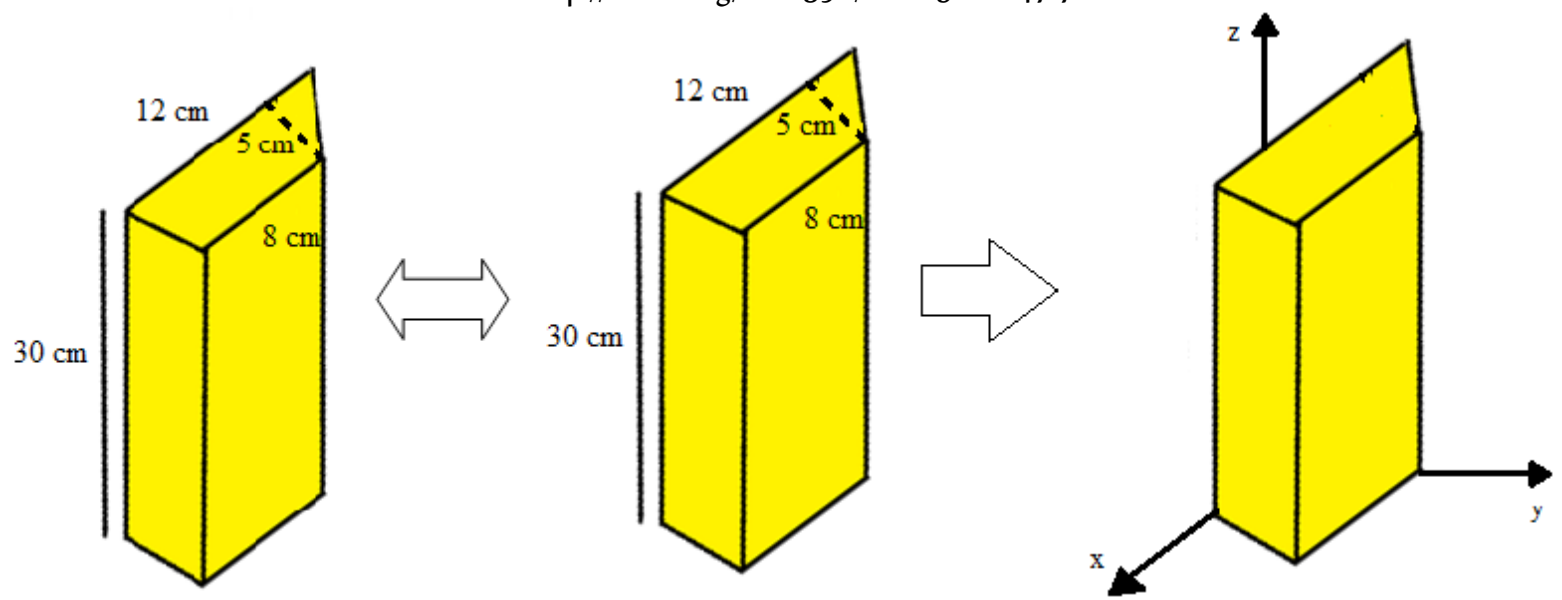

Figura 2 - Modificação na posição da barra de ouro

Fonte: Elaboração dos autores

Na versão em que a barra está de pé, o comprimento da barra não apenas se candidata à ALTURA** (combinação e), mas também representa altura da barra (combinação c), pois está representado verticalmente (eixo y). Com a versão deitada da barra, os estudantes retomaram a representação vertical mais acessível $(5 \mathrm{~cm})$, ignorando o comprimento da barra.

Neste ponto da discussão, cabe questionar se o problema poderia ter sido elaborado de modo a evitar o mapeamento equivocado e se isso seria desejável. Com relação à primeira pergunta, argumentamos que a forma como o problema foi proposto colaborou com a emergência do mapeamento equivocado. De um ponto de vista exclusivamente linguístico, o enunciado do problema leva a inferir que, se 'uma barra de ouro é fundida na forma um prisma' e a 'a altura da barra é $5 \mathrm{~cm}$ ', então 'a altura do prisma é $5 \mathrm{~cm}$ '. Relembremos:

$\mathrm{S}_{1}$ - Uma barra de ouro é fundida na forma de um prisma (premissa implicada do input linguístico);

$\mathrm{S}_{2}-\mathrm{A}$ altura da barra é $5 \mathrm{~cm}$ (premissa implicada do input linguístico);

$\mathrm{S}_{3}-\mathrm{S}_{1} \wedge \mathrm{S}_{2} \rightarrow \mathrm{S}_{4}$ (inferência por modus ponens conjuntivo);

$\mathrm{S}_{4}-\mathrm{A}$ altura do prisma é $5 \mathrm{~cm}$ (conclusão implicada).

O primeiro enunciado apresenta as características da barra de ouro, afirmando que ela é um prisma cuja base é um trapézio. O segundo enunciado fornece as informações do trapézio. $\mathrm{O}$ terceiro enunciado traz a informação referente ao comprimento do prisma. Assim, bastaria substituir o termo 'altura da barra' por 'altura do trapézio' no segundo enunciado para evitar que o estudante construísse a suposição $S_{4}$ de que a altura do prisma é $5 \mathrm{~cm}$. Destaque-se que foi justamente esse enunciado que tornou o terceiro irrelevante, já que o estudante já tinha todas as informações necessárias para o cálculo da área da base e do volume do prisma. Se o terceiro enunciado fosse 'a altura do prisma é $30 \mathrm{~cm}$ ', essa modificação certamente reduziria a possibilidade de equívoco.

Uma barra de ouro é fundida na forma de um prisma cuja base é um trapézio (figura abaixo). As bases desse trapézio medem $8 \mathrm{~cm}$ e $12 \mathrm{~cm}$ e a altura desse trapézio é 5 $\mathrm{cm}$. A altura do prisma é $30 \mathrm{~cm}$. Qual é seu volume?

A hipótese de que a alteração do enunciado evitaria o equívoco é confirmada quando Zetetiké, Campinas, SP, v.25, n.2, maio./ago.2017, p.289-304. 
DOI: http://dx.doi.org/10.20396/zet.v25i2.8647171

se considera a quinta atividade do mesmo conjunto de exercícios do livro (em itálico, a demonstração dos termos adequados):

Um enfeite de acrílico tem como base um trapézio isósceles (figura a seguir). $\mathrm{O}$ trapézio tem $12 \mathrm{~cm}$ de altura e suas bases medem $30 \mathrm{~cm}$ e $10 \mathrm{~cm}$. A peça tem $8 \mathrm{~cm}$ de altura. Qual é o volume dessa peça?

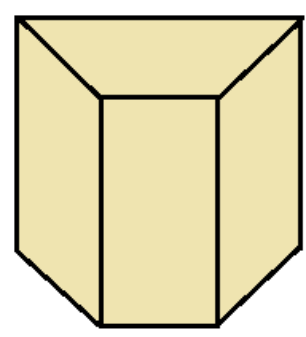

Fonte: (Dante, 2005, p. 372)

Essa atividade demanda conversões e tratamentos semelhantes à nossa atividade alvo. Contudo, diferente daquela, os insumos da atividade são expressos tecnicamente. O primeiro enunciado refere-se às características do enfeite de acrílico, o segundo apresenta as informações sobre a base e o terceiro, sobre a altura desse enfeite. Ao contrário da atividade anterior, os estudantes obtiveram êxito em sua resolução.

Esses resultados sugerem que não somente uma proposição clara das tarefas em língua natural, mas também uma ilustração geométrica mais congruente evita os equívocos encontrados no exercício em questão. Contudo, é justamente nesses espaços polêmicos de conversão que se podem revelar aspectos importantes da aprendizagem. Imaginemos, por exemplo, que todos os estudantes de uma turma acertem todas as conversões e tratamentos de cálculos de volumes de prisma de um conjunto de exercícios técnicos. Esse desempenho teria implicado que eles estão operando com o conceito ALTURA** em vez de ALTURA?

É imperioso que docente deva estar atento a equívocos de conversão, uma vez que os aprendizes ainda não têm o nível de expertise necessário para sobrepairar erros de formulação nos problemas. Todavia, para indivíduos iniciados operando com o conceito ALTURA**, é quase impossível detectar qualquer problema na proposição da questão. Em outros termos, parece tão óbvio ao docente e matemático experiente mapear 'altura da barra' por 'altura do trapézio' e 'comprimento da barra' por 'altura do prisma' quando a barra está deitada, que ele não percebe que ao expressar 'altura da barra', 'altura do trapézio' e 'altura do prisma', mobilizam-se conceitos diferentes. Isso sugere que os equívocos podem não estar apenas centrados na incompetência ou inabilidade do aprendiz.

\section{Considerações finais}

Neste estudo, aplicando o procedimento de compreensão guiado pela noção teórica de relevância, verificamos como estudantes do terceiro ano do ensino médio seguiram uma rota de esforço mínimo no cômputo de efeitos cognitivos, processaram os enunciados de um exercício de cálculo do volume de um prisma em ordem de acessibilidade e pararam quando suas expectativas de relevância foram satisfeitas. Seguindo este caminho, os estudantes 
DOI: http://dx.doi.org/10.20396/zet.v25i2.8647171

concluíram que a altura do prisma era de $5 \mathrm{~cm}$, supostamente porque o enunciado do problema promoveu uma equivalência entre as sequências lexical 'barra de ouro' e 'forma de um prisma'. Com base nessa equivalência, quando o segundo enunciado do problema afirmou que a altura da barra de ouro mede $5 \mathrm{~cm}$, isso autorizou que a altura do prisma também seria de $5 \mathrm{~cm}$, gerando como resultado $250 \mathrm{~cm}^{3}$.

A análise sugere que o equívoco decorre da dupla atribuição de referência ao termo 'altura' nas duas fórmulas. No cálculo da área do trapézio, 'altura da barra' é corretamente mapeada como ALTURA DO TRAPÉZIO; no cálculo do volume do prisma, 'altura da barra' não pode ser mapeada por ALTURA DO PRISMA, gerando um problema de conversão que redunda em erro de cálculo, apesar da correção do tratamento em si.

Além disso, o resultado sugere que não está claro para os estudantes o conceito ALTURA** como a distância que é perpendicular ou que forma um ângulo de $90^{\circ}$ em relação às bases da figura, mas um conceito ALTURA de caráter mais fundamental e intuitivo, que está relacionado com aquilo que é vertical. Esse erro de mapeamento poderia ser facilmente evitado, bastando usar os termos técnicos 'altura do trapézio' e 'altura do prisma' na proposição do problema em língua natural. Todavia, essa providência levaria o docente a não perceber que os alunos não estão compreendendo o conceito matemático em questão. Se, como prediz o mecanismo de compreensão guiado pela relevância, o primeiro conceito que se revela relevante é o que se utiliza, não sendo mobilizado outro, é justamente no equívoco de conversão, como prevê Duval, que o professor tem a possibilidade de perceber não somente que os estudantes não possuem o conceito de altura esclarecido, mas também o quanto a expertise do conceito técnico de altura torna difícil ao docente perceber por que a proposição do problema e a exposição da barra deitada podem causar tanto embaraço.

\section{Referências}

Andrade Filho, B. M. (2010). Processos de conversão de registros em língua natural para linguagem matemática: análise com base na Teoria da Relevância. Dissertação de Mestrado em Ciências da Linguagem. Tubarão: Universidade do Sul de Santa Catarina. Disponível em: http://pergamum.unisul.br/pergamum/pdf/107703_Bazilicio.pdf.

Dante, L. R. (2005). Matemática: volume único. São Paulo: Ática.

Duval, R. (2009). Semiósis e pensamento humano: registros semióticos e aprendizagens intelectuais. São Paulo: Livraria da Física.

Duval, R. (2008). Registros de representações semióticas e funcionamento cognitivo da compreensão em matemática. In S. D. A. Machado (Org.), Aprendizagem em matemática: registros de representação semiótica, 4. ed. (pp. 11-33). Campinas: Papirus.

Michaelis online (2013). Verbete "altura". São Paulo: Melhoramentos. Disponível em: http://michaelis.uol.com.br/moderno/portugues/index.php?lingua=portuguesportugues\&palavra=altura. 
DOI: http://dx.doi.org/10.20396/zet.v25i2.8647171

Rauen, F. J. (2009). Processos interacionais discente/docente em espaço virtual de aprendizagem: análise com base na teoria da relevância. Scripta (PUCMG), 22, 190-217. Disponível em: http://periodicos.pucminas.br/index.php/scripta/article/view/4440/4597.

Sperber, D., \& Wilson, D. (1995). Relevance: communication \& cognition. $2^{\text {nd }}$ ed. Oxford: Blackwell. ( $1^{\text {st }}$ ed. 1986).

Sperber, D., \& Wilson, D. (2001). Relevância: comunicação e cognição. Lisboa: Fundação Calouste Gulbenkian.

Wilson, D. (2004). Pragmatic Theory. London: UCL Linguistics Dept. Retirado em 15 de março, 2005, de: http://www.phon.ucl.ac.uk/home/nick/pragtheory/. 